\title{
A participação cidadã nos processos de inventariação do Patrimônio Cultural Imaterial: casos do Brasil e de Portugal
}

\author{
Lorena Sancho Querol ${ }^{1}$ \\ Elizabete de Castro Mendonça² \\ Ana Flávia Miguel $^{3}$
}

\section{RESUM0 4}

0 campo do patrimônio cultural, apesar do seu histórico relacionado ao contexto colonial e à estruturação associada ao poder socioeconômico, tem vindo ocupar um lugar de centralidade crescente na construção de equilíbrios sociais e de formas de sustentabilidade que valorizam o conhecimento da experiência. Nessa dinâmica, a aprovação da Convenção para a Salvaguarda do Patrimônio Cultural Imaterial (2003) desempenhou um papel importante no reconhecimento dos saberes locais, dos/as seus/suas protagonistas e da sua participação nos processos de inventariação do patrimônio imaterial em prol de uma gestão mais democrática e mais humana do patrimônio. Neste artigo analisamos a dimensão participativa de dois processos de patrimonialização focando a atenção nas dinâmicas utilizadas ao longo dos processos de inventário participativo. Trata-se das Matrizes do Samba, no Rio de Janeiro (Brasil), e do Kola San Jon, na Amadora (Portugal). Com esse objetivo, analisamos as respectivas políticas públicas, o modo como cada um desses processos aconteceu no Brasil e em Portugal e estruturamos, com base em trabalhos de autores/as de referência na teoria da participação, uma ferramenta de análise que permite identificar a natureza participativa e avaliar a qualidade da ação coletiva em cada uma das fases do inventário. Finalmente, apresentamos um conjunto de recomendações que nos aproximam do princípio e das práticas da investigação socialmente responsável, e com o que pretendemos contribuir para a construção de

\footnotetext{
1 Investigadora do Centro de Estudos Sociais, Universidade de Coimbra, Portugal. E-mail: lorenaquerol@gmail.com.

2 Professora do Departamento de Estudos e Processos Museológicos, Universidade Federal do Estado do Rio de Janeiro, Brasil, e Pós-doutoranda no Departamento de Estudos do Património, Universidade do Porto, Portugal. E-mail: elizabete.mendonca@unirio.br.

3 Investigadora no Instituto de Etnomusicologia, Centro de Estudos em Música e Dança, Universidade de Aveiro, Portugal. E-mail: anaflavia@ua.pt.

${ }^{4} \mathrm{O}$ presente artigo apresenta resultados parciais de três projetos e/ou bolsas de pesquisa que as autoras desenvolveram, a saber: bolsa com o apoio do Programa de Professor Visitante Estrangeiro entre 2015 e 2016 (PVE Processo: 1236148, CAPES-Brasil) de que a primeira autora usufruiu; projeto de pós-doutoramento "Documentação em Museu e Salvaguarda do Património Cultural Imaterial: um estudo sobre a contribuição da Gestão Integrada do Património no processo de Democracia Cultural em museus portugueses e brasileiros" que a segunda autora desenvolveu na Universidade do Porto entre 2017 e 2019, bolsa BPD/UI72/5306/ 2016 no âmbito do projeto UID/EAT/00472/2013, na Universidade de Aveiro/INET-md, de que a terceira autora usufruiu.
} 
processos mais participativos e mais democráticos no âmbito da gestão da dimensão imaterial das nossas culturas.

\section{Palavras-chave}

Políticas públicas. Patrimônio Cultural Imaterial. Inventário participativo. Participação cidadã.

\section{ABSTRACT}

The field of cultural heritage has come to occupy a place of increasing centrality in the construction of social balance and sustainability in ways that value the knowledges coming from local experience. In this context, the adoption of a Convention for the Safeguarding of the Intangible Cultural Heritage (2003) played an important role in the recognition of local knowledges, of their protagonists and their participation in the process of inventorying of the intangible heritage in favor of a more democratic and more human management of heritage. The aim of this article is to analyze the participatory dimension of two heritagisation processes focusing on the dynamics used during the participatory inventory process. These are the Arrays of Samba in Rio de Janeiro (Brazil) and Kola San Jon, in Amadora (Portugal). With this goal we analyze the public policies in both countries, as well as the way in which each of these processes has been experienced in Brazil and in Portugal. We create a tool that allows us to identify the participatory nature and assess the quality of the collective action in each of the phases of the inventory. Finally, we present a set of recommendations that approach the principles and practices of socially responsible research. We hope to contribute to the construction of more participatory and more democratic processes within the management of the intangible dimension of our cultures.

\section{KEYWORDS}

Public politics. Intangible Cultural Heritage. Participatory inventories. Citizen participation.

\section{Introdução}

O campo do patrimônio tem ocupado um lugar de centralidade crescente não só pelo desenvolvimento das suas políticas públicas ao longo das últimas décadas, mas também devido ao alargamento do conceito e das práticas a ele associadas, aproximando-se da sociedade com o objetivo de tornar os processos de identificação, estudo, valorização e salvaguarda mais democráticos, participativos e plurais. Soma-se a isto o reconhecimento internacional da sua dimensão imaterial, com a aprovação da Recomendação para a Salvaguarda da Cultura Tradicional e Popular (UNESCO, 1989) e da Convenção para a Salvaguarda do 
Patrimônio Cultural Imaterial (UNESCO, 2003). Esses documentos procuram desancorar-se da linguagem hegemônica e hermética e do foco no estatuto fechado e formal de patrimônio que as caracteriza (PEIXOTO, 2017), tentando colocar a ênfase na dimensão viva da cultura, em processos de patrimonialização que privilegiam a participação ativa da sociedade e na gestão partilhada dos bens patrimonializados, com o objetivo de legitimar de forma democrática a razão ontológica do conceito 5 .

Essa reterritorialização conceptual e metodológica envolve diferentes desafios. Se, por um lado, pressupõe uma mudança de paradigma essencial para superar as questões relacionadas com o discurso eurocêntrico do patrimônio ${ }^{6}$, por outro lado, e contrariando a tendência dicotômica que insiste em definir fronteiras conceituais fechadas entre patrimônio material e imaterial, o conceito de patrimônio cultural imaterial (PCI) permitiu-nos perceber até que ponto as várias dimensões de um bem cultural se complementam de forma indissociável. Finalmente, coloca o desafio de agir com a sociedade, reconhecendo a centralidade das populações criadoras, conhecedoras e utilizadoras dos bens, no processo de inventariação que conduz à patrimonialização e à salvaguarda.

Nesse contexto, no qual o inventário participativo $(\mathrm{IP})^{7}$ pode ser a ferramenta central dos processos de salvaguarda, e porque acreditamos ativamente na necessidade de democratizarmos o conceito de patrimônio e as práticas que lhe estão associadas, optamos por analisar a dimensão participativa do IP em dois países unidos por uma história partilhada: Brasil e Portugal.

Selecionamos processos de bens que foram inventariados e registrados como patrimônio cultural imaterial em cada um desses países. Trata-se de processos que resultam da aplicação das respectivas políticas públicas na área do patrimônio

\footnotetext{
${ }^{5}$ Apesar de não ser foco analítico deste artigo, o processo histórico de construção da categoria "patrimônio cultural" não pode ser naturalizada. As suas noções e práticas foram historicamente vinculadas ao projeto humanista do Ocidente moderno, ao contexto de estruturas de poder coloniais, à seleção dos processos de patrimonialização e a ações problemáticas de "objetificação cultural". Sobre tais assuntos, ver autores como: Handler (1988 e 1994).

Apesar de estarmos cientes desse processo histórico e de como isso repercute até a atualidade nas ações de patrimonialização e salvaguarda de bens materiais ou imateriais, a proposta deste artigo é refletir sobre metodologias e ações de patrimonialização que busquem auxiliar em processos de participação cidadã emancipadores no domínio do patrimônio cultural.

${ }^{6}$ Mais conhecido como Discurso Autorizado do Patrimônio ou Authorized Heritage Discourse. Ver Laurajane Smith (2006).

7 Referimo-nos aqui à variante democrática desta função patrimonial, que definimos como "a intervenção de pessoas e comunidades na identificação e na documentação dos seus recursos culturais, o que envolve o seu reconhecimento como elementos de identidade local e pessoal, isto é, como patrimônio cultural" (SANCHO QUEROL, 2013, p. 181)
} 
(decreto $\mathrm{n}^{\circ} 3551$ de 2000 no Brasil e decreto-lei 139/2009 em Portugal) e, simultaneamente, de processos com componentes afins: (1) ambos refletem a dimensão de práticas performativas de matriz africana que manifesta de um e de outro lado do Atlântico; (2) ambos foram solicitados pela comunidade a que se encontram ligados. Referimo-nos às Matrizes do Samba, no Rio de Janeiro, e ao Kola San Jon (KSJ), na Amadora.

A partir desses dois percursos, queremos refletir sobre os conceitos, os métodos e as práticas definidos no âmbito das políticas públicas para a salvaguarda do PCI no Brasil e em Portugal. Queremos saber quais as naturezas e as intensidades participativas que caracterizam a sua ferramenta-chave, o IP (SANCHO QUEROL, 2016, p. 383) e como foi implementado. Queremos saber quais os seus (d)efeitos, (im)possibilidades e (im)pactos ao nível do desenvolvimento cultural das respectivas comunidades, da implementação de processos de valorização e salvaguarda verdadeiramente inclusivos, da construção de uma necessária e urgente democracia patrimonial. Achamos que, quando plenamente participativos em cada uma das suas fases, os IP constituem uma ferramenta de investigação responsável ${ }^{8}$, levando o patrimônio a incorporar novas funções ao nível do desenvolvimento cultural da sociedade.

Ao longo das próximas páginas apresentamos as políticas de patrimônio imaterial de cada um desses países, seus objetivos e critérios de atuação. Posteriormente, analisamos os processos de inventário das manifestações selecionadas e procedemos, em primeiro lugar, à definição de uma métrica de análise da natureza e da intensidade participativa das diferentes fases do IP e, em segundo lugar, à realização de um estudo comparativo das práticas participativas utilizadas. Finalmente, aproximamo-nos do campo da "society friendly research" 9 para cruzar olhares metodológicos, com o objetivo de refletir sobre algumas questões éticas e práticas que nos parece importante definir no campo dos estudos do patrimônio e, mais concretamente, no contexto da salvaguarda do PCI.

Queremos contribuir para uma reflexão em torno do conceito e das práticas participativas que têm caracterizado os processos de salvaguarda ativa (SANCHO QUEROL, 2016, pp. 357-360) e também das afinações que se tornam necessárias, sendo este o motivo que nos leva a partilhar as nossas experiências numa escrita

\footnotetext{
${ }^{8}$ Investigação e Inovação Responsável (IIR) ou Responsible Research and Innovation (RRI) é a denominação utilizada pela Comissão Europeia nos seus programas sobre "Ciência e Sociedade" (2014-2020) para se referir à pesquisa inovadora envolvendo a sociedade de forma inclusiva e sustentável ao longo dos referidos processos. Mais informação sobre RRI em: https://www.rritools.eu/
}

${ }^{9}$ Esta é outra denominação para o conceito referido na nota anterior. 
plural e atenta aos desafios de um inventariar coletivo.

\section{0 reconhecimento do PCI e a construção das ferramentas nacionais de salvaguarda no Brasil e em Portugal}

As políticas públicas para o PCI no Brasil e em Portugal apresentam convergências no que diz respeito às diretrizes, aos princípios e à estrutura dos seus procedimentos. Porém, também, apresentam particularidades no que se refere ao conceito-chave que rege os inventários (no Brasil utiliza-se "Referências Culturais" e, em Portugal, "Património Cultural Imaterial") e ao próprio entendimento do modelo oficial de inventário disponibilizado pelos governos. Tais particularidades estão baseadas nas realidades culturais, administrativas e históricas que regem as políticas públicas destinadas ao patrimônio cultural de cada país. No entanto, a busca pela classificação de um bem como patrimônio cultural de um país está sempre associada à perspectiva de retornos econômicos, sociais e políticos para os indivíduos ou grupos de indivíduos que detêm os conhecimentos tradicionais associados ao bem, visando, ao mesmo tempo, à transmissão de conhecimentos sobre o bem e à valorização dos/as agentes locais que, em muitos casos, estiveram durante décadas à margem das políticas públicas destinadas à valorização do patrimônio cultural.

\subsection{Brasil e o decreto 3.551: os desafios das políticas públicas direcionadas ao PCI}

O histórico sobre políticas públicas direcionadas ao PCI no Brasil demonstra antecedentes que remetem, no mínimo, à década de 1930. Ao longo do tempo diversas ações referentes à pesquisa, aos inventários e à proteção foram desenvolvidas até a promulgação do decreto 3.551, em 04/08/2000. No entanto, complementado pelas Resoluções n's 01/2006 e 01/2009 e Instrução Normativa $n^{\circ}$ 001/2009, do Instituto do Patrimônio Histórico e Artístico Nacional (Iphan) ${ }^{10}$, o decreto em questão diferencia-se das ações anteriores por constituir o principal marco legal na definição de políticas brasileiras direcionadas ao PCI. Desta forma, constitui o instrumento jurídico de titulação de bens culturais imateriais (Registro) e cria o Programa Nacional do Patrimônio Imaterial (PNPI). Da mesma forma, a

\footnotetext{
${ }^{10}$ Em âmbito federal é o Iphan, por meio do Departamento de Patrimônio Imaterial (DPI), a autarquia do Ministério do Turismo que responde pelas questões referentes ao PCI.
} 
partir desse ato regulamentar, são igualmente estabelecidos os principais instrumentos de políticas públicas federais voltadas ao PCI: o PNPI e o Registro (já citados) bem com o Inventário Nacional de Referências Culturais (INRC) e o Plano de Salvaguarda.

O PNPI é um programa de financiamento, apoio e estímulo a projetos de inventário, reconhecimento e salvaguarda de referências culturais de natureza imaterial. Esse programa busca estabelecer parcerias e captar recursos junto às instituições governamentais e não governamentais para a implementação de políticas específicas direcionadas ao PCI visando à: 1) promoção da inclusão social; 2) melhoria das condições de vida de produtores e de detentores dos conhecimentos patrimonializados; 3) ampliação da participação desses produtores e detentores de conhecimentos nas ações de inventário e de salvaguarda desses bens culturais (IPHAN, 2012) ${ }^{11}$.

O INRC, por sua vez, foi idealizado pelo Iphan com o propósito de descrever os processos socioculturais de criação, de recriação e de transmissão que envolvem tais referências culturais, devendo também identificar e descrever os problemas e as mudanças de significados atribuídos a tais referências ao longo da sua história. Com essas perspectivas, o INRC é considerado nas políticas públicas, ao mesmo tempo, um instrumento técnico e de gestão que visa subsidiar a salvaguarda dos bens inventariados.

A sua aplicação pode ser realizada por quaisquer pessoas físicas ou jurídicas desde que devidamente autorizado pela Gerência de Identificação do Departamento do Patrimônio Imaterial do Iphan (DPI/Iphan) -, e a sua realização deve ser executada em três etapas: levantamento preliminar, identificação e documentação (IPHAN, 2000).

No Brasil, diferentemente da Convenção da Unesco de 2003 (ratificada em 2006) e das premissas estabelecidas internamente por outros países (entre eles Portugal), o conceito-chave que rege a política de patrimonialização de bens de natureza imaterial é o de "Referência Cultural". Antônio Augusto Arantes, antropólogo e um dos idealizadores do INRC, indica que o termo Referência Cultural conceitua "a prática e objeto por meio dos quais os grupos representam, realimentam e modificam a sua identidade e localizam a sua territorialidade. [...] são sentidos de identidades específicas para uma dada coletividade". (ARANTES, 2001, p. 130).

Com base nessa premissa, no âmbito das políticas públicas brasileiras de patrimonialização, é considerada fundamental a distinção entre Referência Cultural e Patrimônio Cultural, porque para uma Referência Cultural adquirir o

${ }^{11}$ Para maior informação ver também: http:/ / portal.iphan.gov.br/pagina/detalhes/761/ 
estatuto de Patrimônio Cultural, é necessário passar pelo processo de patrimonialização, ou seja, pelo processo jurídico e político com o qual "o Estado declara um fato cultural como patrimônio nacional e passa a tratá-lo como bem cultural de interesse público". (VIANNA; TEIXEIRA, 2008, p.122).

Apesar do papel central do Estado no processo de patrimonialização, a relevância de se ter como conceito-chave do inventário o termo "referência cultural" é o entendimento de que o processo de seleção do bem a ser patrimonializado e de atribuição do valor patrimonial que justifica o registro desse bem deve ser dos detentores dos conhecimentos culturais de dados grupos sociais. Neste sentido, tendo como base a diferença entre referência cultural e patrimônio cultural e a função atribuída historicamente aos inventários na política preservacionista brasileira, inventário e titulação (no caso em questão pelo Registro) como patrimônio cultural brasileiro não se confundem (MENDONÇA, 2015, 2017). O inventário não registra a referência como PCI. Ele caracteriza-se como instrumento de conhecimento para a solicitação de registro. São instrumentos de efeitos diferentes, "embora ambos sejam [...] vocacionados para a proteção do patrimônio cultural”. (MIRANDA, 2008).

O Registro, por sua vez, caracteriza-se como um instrumento legal de reconhecimento da referência cultural como PCI. Um dos meios desse reconhecimento é a inscrição em um ou mais dos quatro Livros de Registro estabelecidos pelo decreto, ou seja: I) Saberes: "conhecimentos e modos de fazer enraizados no cotidiano das comunidades; II) Celebrações: "rituais e festas que marcam a vivência coletiva do trabalho, da religiosidade, do entretenimento e de outras práticas da vida social"; III) Formas de expressão: "manifestações literárias, musicais, plásticas, cênicas e lúdicas"; IV) Lugares: "mercados, feiras, santuários, praças e demais espaços onde se concentram e se reproduzem práticas culturais coletivas". (IPHAN, 2000, p. 26).

Como critério fundamental para o pedido de registro está a relevância histórica e contínua da referência cultural para a sociedade brasileira bem como para a memória e a identidade nacional. Esse pedido, conforme especifica o Decreto 3.551 de 2000 que orienta a política de patrimônio imaterial, deve conter a manifestação explícita de interesse dos/as detentores/as e/ou de grupos e/ou associações que os/as representem.

Da mesma forma, considerando a dinâmica cultural dos bens imateriais, $\mathrm{o}$ decreto determina a reavaliação do registro no mínimo a cada 10 anos para verificar se ocorreram mudanças significativas que descaracterizaram os motivos que levaram à titulação, bem como os impactos do próprio processo de registro.

O processo de pedido de registro deve conter, entre outros documentos, o plano 
de salvaguarda. Esse plano consiste na identificação e detalhamento das linhas de ação que precisam ser planejadas e desenvolvidas a curto, a médio e a longo prazos com os objetivos de apoiar e fomentar a continuidade dos bens culturais e os saberes e fazeres vinculados a eles nos respectivos contextos socioculturais e históricos. Deve ser formulado a partir do inventário, de pesquisas complementares e do diálogo contínuo com os/as detentores/as e agentes da sociedade diretamente ligados/as ao bem ${ }^{12}$.

Os documentos produzidos no âmbito das políticas de PCI brasileiras, bem como as análises sobre os mesmos realizadas por autores como Arantes (2001), Fonseca (2004), Castro e Fonseca (2008), Silvestrin e Dianovsky (2017), entre outros, permitem-nos perceber que as políticas públicas para PCI buscam o reconhecimento da diversidade cultural brasileira e a participação efetiva de pessoas e de grupos detentores dos conhecimentos culturais em todos os processos de inventário, reconhecimento e salvaguarda das referências culturais registradas, privilegiando a inclusão social e a dimensão coletiva do $\mathrm{PCI}$. Na prática, os projetos de inventário e salvaguarda são fundamentais para que o PNPI execute uma de suas atribuições: a "concepção e a adoção de indicadores para acompanhamento e avaliação das ações" (IPHAN, 2012)13, do grau de envolvimento dos/as detentores/as.

\subsection{Portugal e a definição de uma gramática coletiva para o Património Cultural}

Segundo Paulo Costa (2013), a extinção do Departamento de Etnologia do Instituto Português do Património Cultural em 1989 coincide com o início de um período de ausência de políticas de valorização do PCI, que durou cerca de vinte anos. Esse período culminou com o processo legislativo de ratificação da Convenção para a Salvaguarda do PCI (agosto de 2007) e que ficou concluído em agosto de 2008 com a criação do Instituto dos Museus e da Conservação (IMC), mais tarde substituído pela Direção-Geral do Património Cultural (DGPC) (COSTA, 2013, p. 93). Entre os anos de 2007 e de 2011, o IMC implementou um conjunto de políticas públicas:

\footnotetext{
12 Em 05/06/2009, foi publicada a Resolução n. 1 sobre a estruturação do processo de pedido de inscrição de referências culturais imateriais na Lista dos Bens em Necessidade de Salvaguarda Urgente e na Lista Representativa do Patrimônio Cultural da UNESCO. No Brasil, a prática é, em primeiro lugar, o bem cultural ser reconhecido em âmbito federal (pelo Iphan) e, posteriormente, encaminhada a solicitação de reconhecimento à UNESCO.
}

13 Ver nota 7. 
(...) ancorando-se nos princípios, nos conceitos e nos mecanismos fundamentais de salvaguarda do PCI instituídos pela Convenção, visando a sua aplicação em território nacional de forma conjugada e em harmonia com o previamente disposto na atual Lei de Bases do Património Cultural, em vigor desde 2001, e, naturalmente, tendo como objetivos divulgar não apenas a Convenção à escala nacional mas também o próprio papel da UNESCO como organização de referência internacional na área do PCI. (opus cit., p. 94).

A criação da Matriz PCI ${ }^{14}$ em 2011, uma base de dados on-line de livre acesso, na qual consta a informação de suporte ao Inventário Nacional do Património Cultural Imaterial (INPCI), é o momento que corresponde com a conclusão da implementação de políticas públicas para o PCI.

A proteção do PCI em Portugal é regulada por diplomas que resultam de um trabalho de análise de documentos relativos ao PCI. Os exemplos de práticas adotadas por países que tinham experiência na implementação de inventários de PCI, como o Brasil ou a Espanha, são também inspiradores na elaboração da estratégia portuguesa (COSTA, 2013, p. 95). Finalmente, foi dada uma especial atenção à Lei nº7 107/2001 de 8 de setembro, que estabelece as bases de política e do regime de proteção e valorização do patrimônio cultural. É desta forma que em 15/06/2009 é publicado o decreto-lei n. ${ }^{\circ} 139 / 2009$, que estabelece o regime jurídico de salvaguarda do patrimônio cultural imaterial. Esse decreto-lei foi, entretanto, revisto e atualizado pelo decreto-lei n. ${ }^{0} 149 / 2015$, no que diz respeito à integração na Direção-Geral do Património Cultural das competências da extinta Comissão para o Património Cultural Imaterial. Por último, em 9/04/2010 é publicada a Portaria n. ${ }^{\circ} 196 / 2010$, que estabelece o procedimento de inventariação do PCI.

A designação do INPCI como instrumento fundamental para a concretização dos processos de patrimonialização da cultura imaterial e os procedimentos para a proteção do PCI são estabelecidos no decreto-lei n. ${ }^{\circ} 139 / 2009$. É, no entanto, o decreto-lei n. ${ }^{0} 149 / 2015$ que esclarece algumas das questões centrais para a proteção do PCI, que resultam da Convenção (2003), das quais destacamos quatro (MIGUEL, 2016, p. 67-69):

1. a ênfase colocada no lugar central que comunidades, grupos e indivíduos ocupam nos processos de inventariação do PCI;

2. o caráter participativo do INPCI;

3. a obrigatoriedade de inscrição no INPCI para ser possível uma posterior candidatura à "Lista Representativa do Património Cultural Imaterial da

${ }^{14}$ A Matriz PCI está disponível em: http://www.matrizpci.dgpc.pt/matrizpci.web/home.aspx 
Humanidade" ou à "Lista do Património Cultural Imaterial que necessita de Salvaguarda Urgente";

4. a extinção da Comissão para o Património Cultural Imaterial cujas atribuições consultivas foram integradas no Conselho Nacional de Cultura e as atribuições instrutórias e de decisão na DGPC.

Já as questões mais técnicas, a ficha de inventário, a documentação obrigatória a integrar o pedido de inventariação, as normas de preenchimento dos formulários, os parâmetros e as condições dos dossiês de candidatura para pedidos de inventariação são indicados na portaria n. ${ }^{\circ} 169 / 2010$. Apesar de a portaria apenas mencionar o recurso a suportes escritos, “(...) registros fotográficos, fílmicos ou videográficos e sonoros que contribuam para a devida caracterização documental da mesma manifestação" (portaria n. ${ }^{0} 169 / 2010$ : 1164) e, portanto, não impor a criação de um documentário audiovisual, esta foi uma prática importante no processo de elaboração da candidatura do KSJ ao INPCI (ver 3.3).

\section{As Matrizes do Samba e o Kola San Jon: inventário, registro e novas formas de afirmação}

\subsection{Os critérios de seleção dos inventários e as suas realidades}

A escolha dos processos de inventariação que aqui analisamos surgiu com base na natureza das manifestações e na proximidade que duas das autoras deste artigo têm, na qualidade de pesquisadoras, com essas manifestações e com os respectivos processos de inventariação. A partir daí, fomos percebendo que existiam outros fatores que reforçavam a nossa escolha e que nos permitiriam aprofundar aspectos inovadores ao longo do estudo, ao mesmo tempo que alimentariam a reflexão em torno da dimensão participativa dessas formas de inventário. Assim, os IP escolhidos:

a) Apresentam uma matriz africana que reflete as relações históricas e que vincula sentidos de vida de um e do outro lado do oceano. Trata-se, portanto, de manifestações que partilham uma condição diaspórica.

b) As duas experiências foram dinamizadas pela própria comunidade. Nesses dois casos o papel da comunidade foi central como ponto de partida dos processos e como elemento decisor em cada uma das suas fases. Consequentemente, as comunidades configuram-se como principais beneficiárias dos resultados obtidos no tempo. 
c) Traduzem-se em processos de participação ativa15 (BORDENAVE, 1983, p. 22-23), que em alguns casos desembocam em participação plena16 (PATEMAN, 1992, pp. 70-71), dentre os quais podemos destacar as práticas de investigação partilhada (SARDO, 2018).

d) Refletem um trabalho interdisciplinar (Estudos do Patrimônio, História, Etnomusicologia, Museologia, Comunicação Multimédia, Design, Antropologia) contribuindo para uma des-hierarquização de saberes, para a construção de novos equilíbrios e para uma progressiva abertura de processos, de equipes e de formas de conhecimento que se complementam.

e) Promovem a equidade de status entre diferentes áreas do conhecimento. Pela natureza das manifestações, com esse tipo de inventários, a Etnomusicologia abandona o status de disciplina que estuda "saberes subjugados" na hierarquia do conhecimento, para transformar o paradigma do trabalho de campo "exótico" na inevitabilidade de novos campos "domésticos" de estudo (MIGUEL, 2016, p. 234) equiparáveis aos campos hegemônicos do conhecimento.

Finalmente, queremos referir que as análises que aqui nos propomos fazer têm como marco inicial a mobilização da comunidade para processos de inventariação, o que, no caso do Brasil, teve lugar em 2004 e, no caso português, em 2012.

\subsection{0 reconhecimento das Matrizes do Samba do Rio de Janeiro como PCI no Brasil}

Segundo o Dossiê de pedido do Registro das Matrizes do Samba como PCI (IPHAN 2014, p. 15), o samba está vinculado a origens africanas e a um histórico de resistência étnica (negra) e religiosa (do candomblé) na cidade do Rio de Janeiro. Com base nisso e no princípio de continuidade histórica e de sociabilidade, fundamentais para uma referência cultural ser titulada como PCI, as Matrizes do Samba no Rio de Janeiro ${ }^{17}$ são representadas no processo de pesquisa para o INRC

\footnotetext{
${ }^{15}$ Segundo Bordenave, diferentemente da Participação Passiva, que é baseada no "tomar parte de", a Participação Ativa é baseada no "fazer parte de".

${ }^{16}$ Segundo Pateman, a Participação Plena acontece naqueles processos em que todas as pessoas que integram um órgão de decisão têm o mesmo poder para tomar a decisão final.

17 O samba não está restrito ao Rio de Janeiro, por isso utiliza-se a preposição "no" para desenvolvimento do seu inventário e registro.
} 
por: "Partido-alto", "Samba de terreiro" e "Samba-enredo". Conforme explicado no mesmo texto (opus cit, p. 15), o termo "matrizes do samba" refere-se a três das variações musicais e de dança que sustentam e dão origem ao que hoje se designa "samba carioca".

O Partido-alto nasceu das rodas de batucada. É uma modalidade de samba que se define pelas suas características musicais e poéticas. Habitualmente tem um tema que funciona como base para a sequência de versos. Dois ou mais partideiros cantam em forma de desafio. O grupo marca ${ }^{18} \mathrm{o}$ compasso com as palmas das mãos e canta o refrão. No centro da roda um/a participante samba e convida outro/a participante com um gesto ou ginga de corpo para ocupar o centro (IPHAN, 2014, p. 24).

O Samba de terreiro recebe esse nome devido ao local onde era praticado - o terreiro - compreendido, neste caso, como a "área comum de uma escola de samba". Apresenta uma grande variedade temática (experiências da vida, amor, exaltação à escola e ao próprio samba) e estilística, sendo "caracterizado mais como uma prática sociomusical do que propriamente como um tipo específico de samba". (IPHAN, 2014, p. 31).

O Samba-enredo relaciona-se com a estruturação das escolas de samba e dos desfiles carnavalescos. É composto de versos que narram melódica e poeticamente uma "história"/enredo. Agrega "características dos dois primeiros subgêneros descritos como, por exemplo, a presença marcante do refrão e a inclusão, quase sempre nas entrelinhas, de experiências e sentimentos dos sambistas" (IPHAN, 2014, p. 15). Porém, por ser o único diretamente vinculado a políticas turísticas é: 1) a variação que, ao contrário das demais, ganhou mais espaço nas quadras das escolas de samba; 2) o mais conhecido das três matrizes e 3) o único que está desvinculado de planos de salvaguarda, por receber altos recursos públicos e empresariais.

A configuração do pedido de registro iniciou-se em 2004, motivada pelo reconhecimento do Samba de Roda (Bahia) como PCI brasileiro. Um segmento dos sambistas do Rio de Janeiro sentiu-se descontente pelo fato de o samba carioca ser mais conhecido mundialmente e não ter sido reconhecido primeiro. Desta forma, estimulados pela sambista Leci Brandão, buscaram o Centro Cultural Cartola (CCC) - hoje Museu do Samba - para solicitar o registro.

O percurso institucional do CCC remonta a 2001 como organização sem fins lucrativos. A sua finalidade era estimular jovens moradores do Morro da Mangueira e adjacências na identificação de referências culturais nas comunidades

${ }^{18}$ Neste contexto a designação samba funciona como sinônimo de dança. 
em que residem, tendo como base dessa iniciativa o (re)conhecimento das obras e do histórico de vida de Angenor de Oliveira (Cartola) - compositor e um dos fundadores da escola de samba Estação Primeira de Mangueira - e de sua esposa Euzébia Silva de Oliveira (Dona Zica), baluarte da mesma escola. No entanto, os propósitos institucionais se ampliaram em 2004, quando se tornou responsável pelo lançamento de diversas ações que vislumbravam a titulação do Samba Carioca como PCI. O primeiro passo dado, nesse ano, foi o projeto "Samba Patrimônio da Humanidade", que teve por objetivo o encaminhamento à Unesco de uma proposta de transformar o samba em Obra-prima do Patrimônio Oral e Imaterial da Humanidade (NOGUEIRA, 2015). Esse projeto não obteve êxito no que se refere à titulação pela Unesco, mas proporcionou o início do levantamento de fontes documentais sobre o tema e inaugurou uma exposição sobre a história do samba do Rio de Janeiro. Em 2005, foi celebrado o convênio entre o Iphan e o CCC, com interferência da Fundação Cultural Palmares e da Secretaria Especial para Promoção da Igualdade Racial (SEPPIR). O objetivo do convênio foi realizar uma pesquisa para a instrução do processo de registro do Samba Carioca como Patrimônio Imaterial. Em 2005, o CCC tornou-se responsável pelo inventário e pela instrução do processo de registro do PCI no contexto brasileiro. No mesmo ano, a instituição também passou a ser reconhecida como Ponto de Cultura ${ }^{19}$ pelo Ministério da Cultura. O seu escopo de atuação passa de ações que têm como beneficiários diretos os moradores do Morro da Mangueira e adjacência para as comunidades sambistas no Rio de Janeiro.

O percurso até a titulação desse bem como Patrimônio Cultural do Brasil com a inscrição no Livro de Registro de Formas de Expressão levou três anos, efetivandose em 2007. No âmbito das ações do Pontão de Cultura ${ }^{20}$ Memória do Samba Carioca, em 2009 o CCC foi reconhecido pelo Iphan como um Centro de Referência de Pesquisa e Documentação do Samba do Rio de Janeiro. Como indicado pela então Diretora Executiva do CCC e coordenadora do inventário e pedido de registro:

${ }^{19}$ Ponto de Cultura, um eixo estruturante do Programa Cultura Viva, do extinto Ministério da Cultura, é criado para "estimular os pontos vitais de expressão da cultura brasileira, por meio de recursos que potencializassem suas ações e dinamizassem sua comunicação" (SARTOR, 2011, pp. 102-103).

${ }^{20}$ O Centro Cultural Cartola passou de Ponto a Pontão de Cultura Memória do Samba Carioca no âmbito do Plano de Salvaguarda das Matrizes do Samba no Rio de Janeiro, tendo este sido este um dos bens indicados pelo IPHAN para tal fim. "O Pontão de Cultura é considerado o instrumento de promoção do intercâmbio e difusão cultural, baseados na articulação de Pontos de Cultura em rede e no apoio a iniciativas que integrem as diferentes linguagens e expressões artísticas." (SARTOR, 2011, p. 115). No caso específico do CCC, o Pontão articula ações para as comunidades sambistas do Rio de Janeiro. 
A importância do Registro trouxe para os detentores a consciência do valor dos bens registrados, é ainda um instrumento político importante. Para o samba resultou na criação do Museu do Samba - um lugar de memória e vivência das Matrizes do Samba do Rio de Janeiro, reconhecidas como Patrimônio Cultural do Brasil, uma iniciativa com total protagonismo social. (NOGUEIRA apud IPHAN, 2015, p. 2-3).

No que se refere especificamente ao processo de inventário, a mesma coordenadora afirma "compreender a metodologia do INRC e aplicá-lo não foi uma tarefa simples" (NOGUEIRA, 2015). Ao longo da pesquisa, a equipe precisou redefinir o objeto de estudo, optando pelas variações do samba citadas. O recorte territorial definido foram as localidades (bairros) nas quais estão inseridas as seis escolas de samba consideradas como representativas da história e da constituição das matrizes: as escolas Estácio de Sá, Império Serrano, Estação Primeira de Mangueira, Portela, Acadêmicos do Salgueiro e Vila Isabel. Esse processo de seleção, apesar de necessário, ressalta um impasse no que se refere à identificação dos detentores desses conhecimentos tradicionais, pois deixa à margem das pesquisas para inventário grupos de sambistas que precisam ser incluídos nos planos de salvaguarda, já que a complexibilidade e a diversidade do samba assim o exigem.

As etapas metodológicas que configuraram o inventário foram: 1) Levantamento Preliminar de fontes e mapeamento cultural temático das referências culturais nas localidades; 2) Identificação ${ }^{21}$ - descrição sistemática, tipificação das matrizes e mapeamento da sua relação com outras referências culturais ${ }^{22}$; 3) Documentação - análise de dados para indicação detalhada dos aspectos relativos aos processos de formação, produção, reprodução e transmissão das referências culturais, bem como produção de documentação audiovisual e inserção dos dados nas fichas do INRC. Paralelamente a essas etapas foram realizadas reuniões, debates e encontros para desenvolver o projeto (NOGUEIRA, 2015, p. 77-78).

Seguindo a orientação do Iphan para a instrumentalização do pedido de registro de patrimônio imaterial, foi encaminhado a esse Instituto um dossiê composto por um texto explicativo e descritivo sobre os processos históricos,

\footnotetext{
${ }^{21}$ Categorias como identificação, documentação, descrição sistemática ou mapeamento, entre outras, citadas neste artigo, permitem estruturar processos de inventário e, também analisar, debater e refletir em torno das diversas matizes, dimensões e perspectivas utilizadas no campo patrimonial. Neste artigo não entraremos nesse assunto, por não constituir o foco do estudo aqui apresentado.

22 Estão associadas a essas variações do samba: comidas, danças, roupas, instrumentos musicais, ritmos, poesia, lugares e símbolos (ver NOGUEIRA 2015, p. 76).
} 
socioculturais e estruturais das Matrizes do Samba, recomendações de salvaguarda e identificação de detentores/as de conhecimentos. Esse dossiê foi acompanhado das fichas do INRC preenchidas, um documentário, CDs e DVDs, livros e documentos textuais referentes ao recorte da pesquisa. A solicitação de registro foi assinada pelo Centro Cultural Cartola, a Liesa, a AESCRJ - entidades representativas das escolas de samba - e diferentes segmentos de sambistas: passistas, compositores/as, ritmistas, Velhas Guardas e baianas.

\subsection{0 reconhecimento do Kola San Jon como PCI em Portugal}

O KSJ é uma prática performativa de matriz cabo-verdiana centrada na Festa de São João Baptista, que veio para Portugal com os migrantes cabo-verdianos no fim do século XX e se estabeleceu no bairro da Cova da Moura (Kova M), na área metropolitana de Lisboa. Em Cabo Verde, o KSJ acontece, em particular, nas ilhas de Santo Antão, São Vicente e São Nicolau, nas quais a performance inclui a música (tambores, apitos e palavra cantada), a dança (com o golpe de umbigada23) e os artefatos (tais como o navio, os rosários, as imagens dos santos juninos, as bandeiras, as espadas e os trajes). Uma das celebrações mais emblemáticas acontece em Porto Novo, na ilha de Santo Antão, durante o mês de junho ${ }^{24}$ (MIGUEL, 2017).

Após a independência de Cabo Verde, em 5/07/1975, a cidade de Lisboa constituiu um destino de migrantes que se fixaram na Kova M. A Associação Cultural Moinho da Juventude (ACMJ) é uma associação sem fins lucrativos e um exemplo do processo referido. É constituída por iniciativa de um grupo de moradores (1987) que, num processo que em crioulo é designado "Djunta Mo" (significa juntar as mãos), procurou encontrar soluções para problemas econômicos, sociais e de cidadania do bairro:

ACMJ (founded in 1987) is one of several organizations and associations, with humanitarian profiles, that appeared as part of a long process that followed the arrival of democracy in 1974, in which the organizations played an important role in the struggle for equality and citizens' rights for immigrant communities and minorities. (MIGUEL, 2017, p. 440).

\footnotetext{
${ }^{23}$ Movimento coreográfico em que os corpos de um par de dançarinos/as ao aproximarem-se se tocam na zona do ventre e logo depois se afastam para recomeçar o movimento coreográfico (MIGUEL 2010, p. 96).

${ }^{24}$ Para uma descrição mais detalhada do KSJ sugerimos a leitura de Kola San Jon, Música, Dança e identidades Cabo-Verdianas (MIGUEL 2010) e de Classificar o património (re)classificando as identidades. A inscrição do Kola San Jon na lista portuguesa do PCI (MIGUEL; SARDO 2014).
} 
No entanto, o que viria a complementar as componentes anteriormente referidas foi a cultura. Esse fenômeno constatou-se com o acolhimento e a formalização de grupos performativos, tais como o grupo de Batuque Finka Pé, em 1989 (RIBEIRO, 2012) e o grupo de KSJ, em 1991 (MIGUEL, 2010). Foi na Kova M que o KSJ começou a acontecer em 1991 como performance anual formalmente organizada e acolhida institucionalmente pela $\mathrm{ACMJ}{ }^{25}$.

A música adquiriu um papel relevante nesse processo, porque permite uma comunicação privilegiada com os outros, a qual outros aspectos da cultura não permitem. É por essa razão que vários grupos minoritários têm adotado e escolhido a música como forma de se evidenciar, de expor a sua diferença e de construir pontes de diálogo com a sociedade em geral (SARDO, 2010, 2016; MIGUEL, 2016). Sobre esse último aspecto, parece-nos importante referir que é a natureza da música que faz com que ela desempenhe um papel singular na construção de diálogos:

Music travels with his protagonists and is probably the most well equipped human behaviour to hide knowledge as well as to expose it. In fact I can keep a song in my mind for years without singing it, travelling with it for long distances, offering it to another person, mixing it with another song, hiding forbidden words in it, sharing a performance with others, recognising belong- ing sounds, making others identify themselves with "my music" and identifying myself with the music of the other's, communicating through the internet and sending music to the other side of the globe with my cell phone. We can not do this with words; we can not do this with food, neither with dance, or other human behaviours. (SARDO, 2016, p. 156).

No caso da Kova M, ao eleger algumas práticas performativas cabo-verdianas como forma de representação e como forma de representar a diferença quanto ao país de acolhimento e de pertença em relação a Cabo Verde, a ACMJ criou através da música um espaço sem fronteiras:

(...) what makes music special - what makes it special for identity - is that it defines a space without boundaries (a game without frontiers). Music is thus the cultural form best able both to cross borders - sounds carry across fences and walls and oceans, across classes, races and nations (...). (FRITH, 1996).

${ }^{25}$ Para mais informações sobre a ACMJ, sugerimos a consulta do website: http://www.moinhodajuventude.pt/ 
A ACMJ construiu uma plataforma de diálogo com o país de acolhimento e com o próprio país de origem que teve um dos seus pontos altos com a patrimonialização do $\mathrm{KSJ}^{26}$. A iniciativa desse processo partiu do grupo de KSJ, que solicitou a parceria de dois centros de investigação: o INET-md/Universidade de Aveiro, através da etnomusicóloga Ana Flávia Miguel, e o GESTUAL/CIAUD/Universidade de Lisboa, através da antropóloga Júlia Carolino. O KSJ é o primeiro item referente a uma prática com uma origem não portuguesa incluído no INPCI (MIGUEL, 2017, 2016; MIGUEL; SARDO, 2014).

O processo de construção do dossiê de candidatura foi marcado pelo Djunta Mo, ou seja, pela incorporação de agentes culturais, investigadores/as, pessoas próximas do universo da Kova M, membros da ACMJ, membros do grupo de KSJ e habitantes da Kova M, em momentos de trabalho periódicos. Digamos que várias pessoas "juntaram as mãos", por vezes em reuniões coletivas e por vezes em momentos de trabalho individual, e contribuíram para a construção e organização da documentação exigida para a concepção do dossiê de candidatura. Essa estratégia também foi utilizada na edição do filme da candidatura, que ficou a cargo da equipe da INET-md/UA.

Para concluir, é ainda necessário referir a lista do patrimônio associado à candidatura, que inclui o bairro como patrimônio imóvel. Salientamos esse fato porque desde 2002 o bairro se encontrava em ameaça de demolição. Com essa incorporação, a candidatura do KSJ configurou-se como estratégia de apropriação de ferramentas de políticas públicas para defesa do bairro e da Festa de KSJ, cuja performance está ligada à geografia física e humana do bairro.

\section{A participação vista à lupa: (d)efeitos, (im)possibilidades e (im) pactos nos inventários do Samba e do Kola}

\subsection{Os conceitos e as métricas da análise: definindo uma “Escala de Participação Cidadã" para avaliar os processos de inventário de patrimônio cultural}

Nos campos agitados e transformadores da participação só se aprende a participar participando (BORDENAVE, 1983, p. 74). Com efeito, esse verbo envolve em si mesmo um conjunto de ações interligadas, tais como a escuta significativa (MIGUEL, 2016, p. 231), o pensar e o agir de forma coletiva e a partilha constante

\footnotetext{
${ }^{26}$ Anúncio n⿳323/2013 - “Inscrição do 'Kola San Jon' (Bairro do Alto da Cova da Moura, Amadora) no Inventário Nacional do Património Cultural Imaterial”. Diário da República, 2a Série - N²00 - 16 de outubro de 2013.
} 
de responsabilidades. Neste sentido, exige uma flexibilidade de pensamento e de ação que, além de nos libertar de fórmulas predefinidas, permite-nos dar forma a cada passo do processo à medida que vamos percebendo a melhor maneira de caminhar junto e com as pessoas envolvidas em desafios como o do IP.

Assim, após estudar o desenvolvimento do conceito de participação (SANCHO QUEROL, 2017) e com o objetivo de analisar as práticas utilizadas nos processos de IP, optamos por estruturar, com base nas referências citadas neste tópico e na observação dos processos de inventariação referentes aos objetos de estudos aqui apresentados, uma ferramenta de análise que denominamos: "Escala de Participação Cidadã" (EPC). Partimos das teorias e dos conceitos que consideramos mais pertinentes para identificar a natureza e a intensidade participativas de cada uma das fases dos IP. Incluímos ainda algumas das ideias e conceitos desenvolvidos por Miguel (2016) numa das suas pesquisas recentes.

A "Escala de Participação Cidadã" no domínio do patrimônio cultural (Figura 1) é uma ferramenta de análise que resulta do cruzamento de três propostas de classificação de metodologias participativas que vêm sendo usadas em diversos contextos desde a década de 60 do século XX e que selecionamos pela sua clareza, utilidade e pertinência. Referimo-nos:

a) à "Escada da Participação Cidadã" proposta por Sherry Arnstein em resposta às experiências de participação manipulada como a dos Programas de Ação Comunitária nos EEUU (ARNSTEIN, 2004/1969);

b) à tabela dos "Graus de poder participativo" definida por Juan Bordenave para reconstruir e fortalecer as iniciativas democráticas em vários países de América Latina a partir da década de 80 (BORDENAVE 1983, p. 31);

c) ao "Espectro de Participação Pública" proposto pela International Association for Public Participation ${ }^{27}\left(\mathrm{IAP}^{2}\right.$, 2014) para reforçar a presença das cidadãs e dos cidadãos na elaboração das atuais políticas públicas.

A EPC apresenta as várias formas de participação cidadã organizadas segundo as suas características intrínsecas, o seu enquadramento e os ecos que delas resultam. Neste último caso, baseamo-nos nos produtos que derivam de cada fase de um processo participativo segundo Cohen e Uphoff (2011: 34), para os quais, à medida que as cidadãs e os cidadãos vão assumindo o controle dos processos, passam a constituir resultados relevantes: a decisão compartilhada, a

${ }^{27}$ Os 5 níveis de participação definidos pelo IAP2, no seu Spectrum são informar, consultar, envolver, colaborar e empoderar. Para conhecer o espectro, sugere-se a consulta da respectiva página em: http://www.iap2.org/?page=A5 
implementação coletiva da decisão e também os benefícios ou efeitos transformadores que daí resultam, entre os quais encontramos a construção de conhecimento acadêmico (CA), de conhecimento de experiência (CE) e de saberes tranformadores (ST) ${ }^{28}$, que tomam como referência a "Teoria da Ecologia dos Saberes" (SANTOS, 2007) e também o "Modelo de construção de conhecimento Skopeologias" (MIGUEL, 2016) ${ }^{29}$.

Da mesma forma, referem Cohen e Uphoff (2011), conforme aumenta o nível de controle dos processos aumenta a responsabilidade, pelo que se torna necessária uma avaliação regular, de modo a perceber quais os métodos e as ferramentas que precisam de afinação em cada caso e em cada fase, e se houve implementação dos resultados da avaliação.

Como resultado, a EPC apresenta três opções para análise dos processos que se configuram segundo a sua natureza participativa.

A primeira opção inclui as formas de Participação Dirigida ou não participação que, segundo Arnstein, permitem a quem decide poder "educar" ou "curar" as cidadãs e os cidadãos envolvidos no processo. Como consequência: prevalecem linhas de atuação e produtos dirigidos por grupos dominantes; apenas é produzido Conhecimento Acadêmico $(\mathrm{CA})^{30}$, uma vez que o Conhecimento da Experiência $(C E)^{31}$ não é devidamente valorizado nos processos de pesquisa, de construção e de fruição de novos saberes a diferentes níveis. Essas opções de atuação dificilmente produzem transformações na sociedade local ou abrem novas possibilidades de desenvolvimento coletivo a partir dos conhecimentos produzidos.

A segunda opção inclui as formas de Participação Concedida ou Passiva pelo fato de permitirem "tomar parte de" (BORDENAVE, 1983, p. 22-23). Aqui incluímos três formas de concessão limitada de poder que, segundo Arnstein (o.c.), permitem às cidadãs e aos cidadãos ouvir e serem ouvidos/as, não tendo a certeza de que as suas opiniões sejam aceitas por quem detém o poder, exceto na opção que apresenta maior intensidade participativa: o envolvimento. Trata-se de um tipo de participação sem "musculatura" própria, pois não há garantia de mudança do status quo. Essas três opções são:

\footnotetext{
${ }^{28}$ Saberes Transformadores resultam da partilha de saberes (acadêmicos e da experiência), que acontece através do uso de práticas participativas, cuja permeabilidade permite aceder a diferentes modos de construir o conhecimento (MIGUEL, 2016, p. 226).

${ }^{29}$ Este modelo foi desenvolvido por Miguel durante o processo de pesquisa participativa com o grupo Skopeofonia, na Kova M.

${ }^{30}$ Conhecimento Acadêmico é o conhecimento construído por pessoas do universo acadêmico.

${ }^{31}$ Conhecimento da Experiência é o conhecimento que as cidadãs e os cidadãos constroem ao longo do tempo a partir das suas experiências quotidianas.
} 
1. a Informação do processo em curso - que se traduz numa comunicação unidirecional que não tem por objetivo ouvir as cidadãs e os cidadãos;

2. a Consulta - na qual são auscultadas as opiniões das cidadãs e dos cidadãos, podendo acontecer diferentes níveis de escuta e interação entre as partes envolvidas, em função da sua natureza obrigatória ou facultativa, embora no geral as decisões finais sejam unilaterais e o poder permaneça novamente no mesmo lado;

3. o Envolvimento - que incluímos por considerá-lo um grau de participação superior ao da consulta já que, tal como refere o IAP2 (o.c.), garante que as preocupações e os desejos das cidadãs e dos cidadãos sejam integrados nos processos de decisão, embora o poder de decisão ainda se mantenha do mesmo lado.

Dentre essas opções, são a consulta e, sobretudo, o envolvimento que permitem produzir não só $\mathrm{CA}$, como também $\mathrm{CE}$ construído pelas cidadãs e pelos cidadãos que conhecem a realidade em estudo, embora não possuam títulos acadêmicos que validem formalmente esses saberes. A interligação de diferentes agentes que possuem CA e/ou CE resulta em Saberes Transformadores (ST) capazes de contribuir para uma emancipação cultural sustentável, isto é, na produção de um conhecimento mais aprofundado e atual das realidades em estudo, e também das necessidades existentes ao nível da sua valorização, ressignificação e uso inclusivo e sustentável.

A terceira opção inclui as formas de Participação Emancipadora, também conhecida como Poder Cidadão (Arnstein o.c.), e nela incluímos diferentes graus de participação ativa, isto é, baseada no "fazer parte de" (BORDENAVE, 1983, p. 22-23). Assim, a Cogestão envolve a gestão compartilhada dos processos de ação e de decisão e a negociação de igual para igual com quem detém tradicionalmente o poder, motivo pelo que a própria Arnstein se refere a ela como "parceria". A Delegação de poder reconhece e outorga autonomia às cidadãs e aos cidadãos em diversas partes do processo ou em diferentes campos de atuação. Finalmente, na Autogestão, as cidadãs e os cidadãos detêm por completo o poder de gestão dos processos, motivo pelo qual Arnstein a denomina "controlo cidadão" (o.c.).

Na análise dos IPs optamos por incluir todos esses níveis de participação para perceber quais as naturezas e as intensidades de participação cidadã que foram utilizadas em cada fase, em que estágio de maturidade participativa se encontra atualmente cada uma delas e quais as repercussões e impactos para os/as diferentes agentes envolvidos. 


\section{Figura 1 - Escala da participação cultural no domínio do patrimônio cultural}

\section{ESCALA DE PARTICIPAÇÃOCIDADÃNO DOMÍNIO DO PATRIMÔNIOCULTURAL}

$\left.\begin{array}{l}\text { Autogestão } \\ \text { Delegação } \\ \text { Cogestão }\end{array}\right\}$

\section{PARTICIPAÇÃO EMANCIPADORA}

O quê? Participação cidadã plena por meio de interesses e processos de gestão compartilhada.

Que condições? Participação com comunicação multivocal e avaliação regular que permite melhorar o processo e regenerar os STs.

Que ecos? Decisão compartilhada. Implementação coletiva da decisão. Produção de benefícios socialmente transformadores entre os quais se encontra a produção de CA e de CE de forma equilibrada. Produção de STs emancipadores para a população local.
Envolvimento

Consulta - Facultativa Informação

\section{PARTICIPACÃO CONCEDIDA}

O quê? Concessão limitada de participação cidadãno processo decisório. Atende a interesses de um ou mais grupos. Que condições? Participação com diversos níveis de comunicação; o poder decisório não é compartilhado.

Que ecos? Decisões finais não compartilhadas. Produção de CA e de CE em função do nível de participação cidadã. Pode resultar na produção de ST.

\section{PARTICIPACÃO DIRIGIDA}

Terapia

O quê? Formas ilusórias de participação cidadã dirigidas por agentes externos. Atende aos interesses de um ou mais grupos dominantes.

Manipulação

Que condições? Participação unilateral (não dialógica) desconectada das realidades locais e dos grupos detentores do conhecimento.

Que ecos? Linhas de atuação e produtos dirigidos por grupos dominantes e/ou produção de CA seguindo métodos de pesquisa não inclusivos.

\section{Legenda}

"Escada Poder cidadão". Sherry Arsntein

CA: Conhecimento Acadêmico

"Graus de participaçăo". Juan Bordenave CE: Conhecimento da Experiência

"Espectro Participação Pública". IAP2

"Ecologias de Saberes". Boaventura de Sousa Santos

"Skopeologias". Modelo de construção de conhecimento". Ana Flávia Miguel

Texto nesta cor-criação das autoras do artigo. 


\subsection{Estudo comparativo}

Em seguida apresentamos os resultados obtidos na análise dos processos de IP das Matrizes do Samba e do KSJ a partir da Escala de Participação Cidadã (Quadro 1).

A análise da natureza participativa das ações que integram cada um desses processos de IP está baseada no grau de predominância de uma das opções da Escala da Participação sobre as outras. Convém salientar que não estamos abarcando a totalidade da comunidade detentora dos conhecimentos, e sim representantes designados/as para o efeito, que se imbuíram da tarefa de conduzir os inventários. Para definir o tipo de participação considerou-se a composição formada pelas suas vozes somadas às dos/as pesquisadores/as, dos/as representantes do Estado e de outras instituições parceiras.

Analisamos igualmente os impactos ou benefícios resultantes de cada um desses IP, utilizando não só a perspetiva tradicional (que foca as questões do poder de decisão partilhada), como também novas perspectivas mais abrangentes, como a utilizada por Stage e Ingerslev (2015, p. 132) com enfoque na análise dos benefícios sociais, pessoais-afetivos, materiais e, finalmente, do potencial de mudança das realidades preexistentes. 
Quadro 1 - Análise comparativa dos processos de inventário sob a perspectiva da escala de participação cidadã: as matrizes do samba no Rio de Janeiro (Brasil) e o Kola San Jon em Lisboa (Portugal)

\begin{tabular}{|c|c|c|c|}
\hline \multicolumn{2}{|c|}{ MATRIZES DO SAMBA } & \multicolumn{2}{|c|}{ KOLA SAN JON } \\
\hline AÇÕES & $\begin{array}{l}\text { ANÁLISE DIMENSÃO } \\
\text { PARTICIPATIVA }\end{array}$ & AÇÕES & $\begin{array}{c}\text { ANÁLISE DIMENSÃO } \\
\text { PARTICIPATIVA } \\
\end{array}$ \\
\hline $\begin{array}{l}\text { 1. Idealização da proposta por parte } \\
\text { da comunidade }\end{array}$ & \multirow{2}{*}{$\begin{array}{l}\text { NATUREZA DAS AÇÕES } \\
\text { A maior parte das ações realizadas } \\
\text { tem natureza participativa } \\
\text { emancipadora. }\end{array}$} & $\begin{array}{l}\text { 1. Idealização da proposta por } \\
\text { parte da comunidade }\end{array}$ & \multirow{4}{*}{$\begin{array}{l}\text { NATUREZA DAS AÇÕES } \\
\text { A maior parte das ações } \\
\text { realizadas tem natureza } \\
\text { participativa C ou E. } \\
\text { A única ação D/C (2) é } \\
\text { vinculada às exigências para } \\
\text { registro do bem, determinadas } \\
\text { por decreto-lei. }\end{array}$} \\
\hline 2. Estabelecimento de parcerias & & $\begin{array}{l}\text { 2. Reunião com o responsável do } \\
\text { INPCI para averiguação da } \\
\text { viabilidade da proposta }\end{array}$ & \\
\hline $\begin{array}{l}\text { 3. Realização de exposição, eventos } \\
\text { e desenvolvimento de projetos } \\
\text { paralelos }\end{array}$ & \multirow{4}{*}{$\begin{array}{l}\text { A única ação } \mathrm{D} / \mathrm{C}(5) \text { é vinculada às } \\
\text { exigências para registro do bem, } \\
\text { determinadas por decreto-lei. } \\
\text { As ações C/E }(6,7,8,11,12) \text { requerem } \\
\text { conhecimentos acadêmicos e foram } \\
\text { realizadas pela equipe de } \\
\text { investigadores/as em conjunto com } \\
\text { os/as sambistas e com a equipe do } \\
\text { Iphan. }\end{array}$} & 3. Estabelecimento de parcerias & \\
\hline $\begin{array}{l}\text { 4. Constituição da equipe de } \\
\text { trabalho }\end{array}$ & & $\begin{array}{l}\text { 4. Constituição da equipe de } \\
\text { trabalho }\end{array}$ & \\
\hline $\begin{array}{l}\text { 5. Reunião com instâncias do Iphan } \\
\text { para averiguação da viabilidade da } \\
\text { proposta }\end{array}$ & & $\begin{array}{l}\text { 5. Análise dos formulários e } \\
\text { dados para formalização de } \\
\text { candidatura }\end{array}$ & \multirow{4}{*}{$\begin{array}{l}\text { As ações C e C/E requerem } \\
\text { conhecimentos acadêmicos e } \\
\text { foram realizadas pela equipe de } \\
\text { investigadoras afetas à } \\
\text { candidatura e/ou pelas } \\
\text { investigadoras em conjunto com } \\
\text { o grupo de KSJ e com a equipe } \\
\text { da DGPC ( } 5,6,7,8,9,11) \text {. O } \\
\text { produto final foi sempre } \\
\text { resultado de discussão coletiva } \\
\text { com o grupo KSJ. }\end{array}$} \\
\hline $\begin{array}{l}\text { 6. Definição do bem e da ficha de } \\
\text { identificação e delimitação da área a } \\
\text { inventariar }\end{array}$ & & $\begin{array}{l}\text { 6. Pesquisa e sistematização de } \\
\text { fontes bibliográficas e } \\
\text { documentais }\end{array}$ & \\
\hline $\begin{array}{l}\text { 7. Pesquisa e sistematização de } \\
\text { fontes bibliográficas e documentais }\end{array}$ & \multirow{5}{*}{$\begin{array}{l}\text { As ações E incluem: } \\
\text { a) Idealização por parte da } \\
\text { comunidade sambista }(1) \text {. } \\
\text { b) Definição de recursos humanos e } \\
\text { parcerias, com coordenação de } \\
\text { representantes da comunidade } \\
\text { sambista }(2,4) . \\
\text { c) Decisão de estratégias e de } \\
\text { conteúdos }(3,9,10,13,1415) \text { - } \\
\text { reflete voz ativa dos/as sambistas } \\
\text { em todo o processo. }\end{array}$} & $\begin{array}{l}\text { 7. Trabalho de campo e análise } \\
\text { dos dados }\end{array}$ & \\
\hline $\begin{array}{l}\text { 8. Trabalho de campo e análise dos } \\
\text { dados }\end{array}$ & & $\begin{array}{l}\text { 8. Preenchimento dos } \\
\text { formulários do INPCI }\end{array}$ & \\
\hline 9. Diagnóstico de sustentabilidade & & $\begin{array}{l}\text { 9. Produção de material } \\
\text { audiovisual }\end{array}$ & As ações E incluem: \\
\hline $\begin{array}{l}\text { 10. Mapeamento das relações com } \\
\text { outros bens e práticas }\end{array}$ & & 10. Reuniões trabalho coletivo & $\begin{array}{l}\text { a) Definição de recursos } \\
\text { humanos }(3,4) \text {. }\end{array}$ \\
\hline $\begin{array}{l}\text { 11. Preenchimento dos formulários } \\
\text { do INRC }\end{array}$ & & $\begin{array}{l}\text { 11. Construção do plano de } \\
\text { salvaguarda }\end{array}$ & $\begin{array}{l}\text { b) Construção de conteúdos (6, } \\
\text { 9,11) - destaca o impacto da } \\
\text { mobilização dos membros }\end{array}$ \\
\hline
\end{tabular}




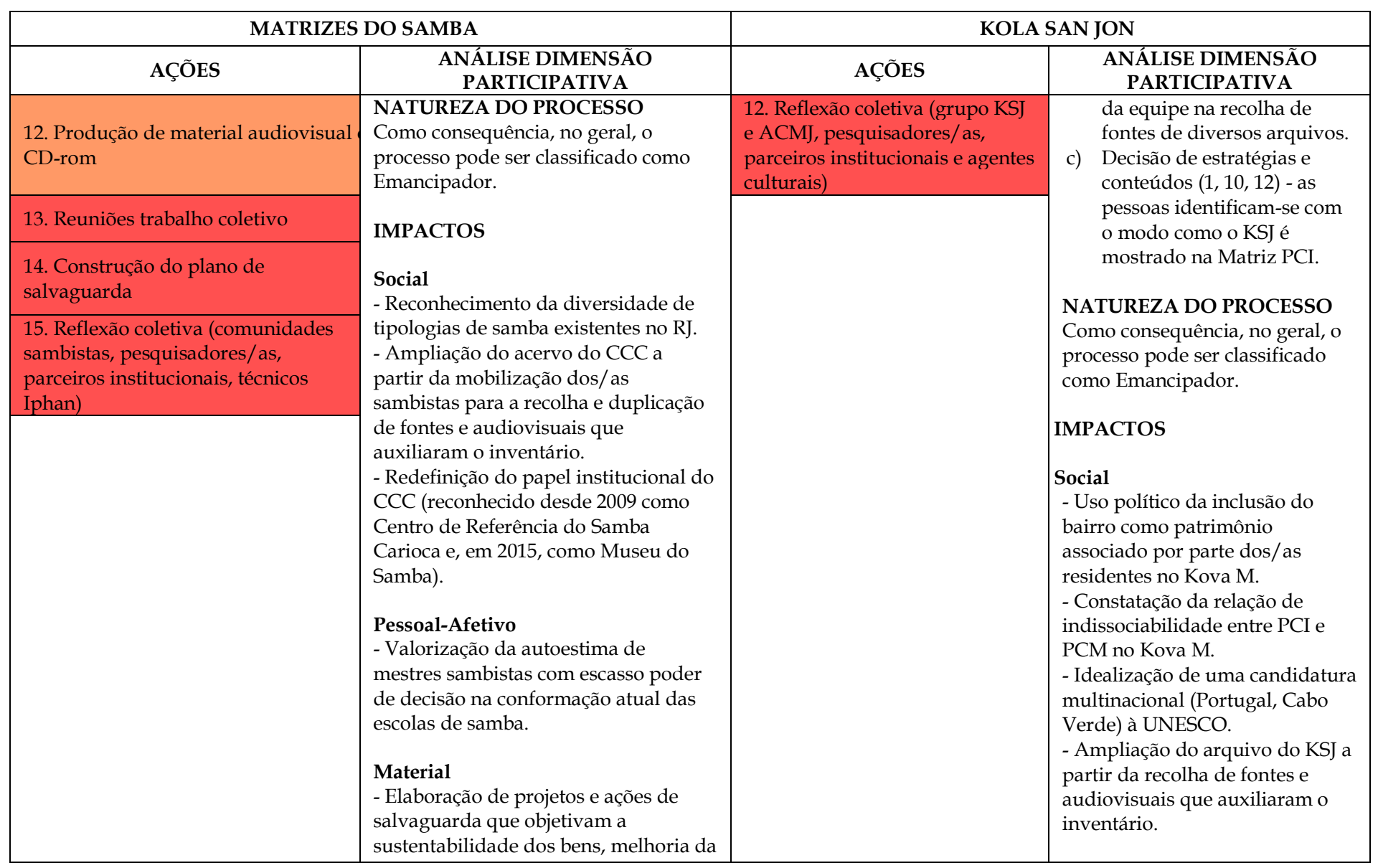




\begin{tabular}{|c|c|c|c|}
\hline \multicolumn{2}{|c|}{ MATRIZES DO SAMBA } & \multicolumn{2}{|c|}{ KOLA SAN JON } \\
\hline AÇÕES & $\begin{array}{l}\text { ANÁLISE DIMENSÃO } \\
\text { PARTICIPATIVA }\end{array}$ & AÇÕES & $\begin{array}{l}\text { ANÁLISE DIMENSÃO } \\
\text { PARTICIPATIVA }\end{array}$ \\
\hline & $\begin{array}{l}\text { condição de vida dos/as } \\
\text { detentores/as de conhecimentos, } \\
\text { fortalecimento de comunidades } \\
\text { sambistas que se encontram } \\
\text { desassistidas de investimentos. } \\
\text { Potencial de Mudança de Realidades } \\
\text { Preexistentes (Criação de Valores ou } \\
\text { de Novas Capacidades?) } \\
\text { - Exercício da prática de advocacy por } \\
\text { parte do Museu do Samba para lutar } \\
\text { por ações dentro do campo das } \\
\text { políticas públicas e outras que se } \\
\text { refletem no campo social e econômico. }\end{array}$ & & $\begin{array}{l}\text { Pessoal-Afetivo } \\
\text { - Valorização da autoestima } \\
\text { coletiva e individualmente do } \\
\text { grupo de KSJ - apresentam-se } \\
\text { como "embaixadores" do KSJ e } \\
\text { do Kova M com "dupla } \\
\text { nacionalidade". } \\
\text { Material } \\
\text { - Elaboração de primeiras ações } \\
\text { de salvaguarda. } \\
\text { Potencial de Mudança de } \\
\text { Realidades Prexistentes } \\
\text { (Criação de Valores ou Novas } \\
\text { Capacidades) } \\
\text { - Incrementação do exercício da } \\
\text { prática de advocacy por parte do } \\
\text { grupo de KSJ e da ACMJ para } \\
\text { lutar por ações dentro do campo } \\
\text { das políticas públicas e outras } \\
\text { que se refletem no campo social } \\
\text { e econômico. }\end{array}$ \\
\hline
\end{tabular}

\begin{tabular}{|l|l|}
\hline Legenda cromática: natureza da ação participativa \\
\hline Participação emancipadora & \\
\hline Participação concedida-emancipadora & \\
\hline Participação concedida & \\
\hline Participação dirigida-concedida & \\
\hline Participação dirigida & \\
\hline
\end{tabular}




\subsection{Repensando os inventários participativos de patrimônio cultural sob a perspectiva da investigação responsável}

Os processos participativos são frequentemente complexos, multidimensionais e ricos em desconexões. Provavelmente é por esse motivo que Stage e Ingerslev (2015, p. 119) chamam a atenção sobre a importância de os desenvolver a partir de duas perspectivas: (1) analítica, para nos permitir entender de que forma se definem as conexões entre os indivíduos, as instituições e os afetos; (2) avaliativa, para nos permitir aceder aos processos de criação de valor e de novas capacidades que resultam dos processos.

Neste sentido, e com o objetivo de alargar a abrangência social dos programas de investigação e inovação, foi recentemente definido em contexto europeu um desafio transversal às várias áreas do saber denominado "Investigação e Inovação Responsável" (IIR) ${ }^{34}$. O conceito de RRI propõe o envolvimento de atores/as sociais diversos/as (academia, cidadania, setor político, setor empresarial, terceiro setor, etc.) durante todo o processo de pesquisa e produção de conhecimento, com o objetivo de promover a relação entre a ciência e a sociedade, criando soluções que vão ao encontro das necessidades e expectativas da sociedade. Curiosamente, quer os compromissos quer a linguagem conceptual da IIR estão em sintonia com as recomendações que emergem da análise apresentada no ponto 4.2., pelo fato de na área dos estudos do patrimônio o envolvimento societal constituir a base essencial de processos como os do IP.

Sob a inspiração da IIR, e a partir das reflexões resultantes da análise apresentada no Quadro 1, elencamos aqui um conjunto de recomendações para os IP concluídos ou em vias de realização, de modo a contribuir para a construção de processos participativos. Deste modo, consideramos necessário que o envolvimento societal assente nas seguintes medidas:

- a representação equilibrada de atores/as, interesses e valores: a) trabalhando em profundidade a inclusão da diversidade, b) mobilizando desde o início os/as detentores/as dos saberes em estudo, c) inserindo o maior número possível de pessoas/grupos representativos;

- a adequação e o respeito dos tempos necessários a um envolvimento estruturador e proativo: logo no início e de forma continuada ao longo do processo;

- a criação de espaços de deliberação abertos à definição de alternativas e ao

34 Ver nota 4. 
exercício de uma comunicação multidirecional responsável, flexível e reflexiva, privilegiando (sempre que possível) o papel dos/as detentores/as de conhecimentos da experiência na coordenação dos processos;

- o envolvimento institucional mediante a sua inclusão nos processos de tomada de decisão e corresponsabilização ao longo do tempo e, ainda, mediante o estabelecimento de redes de parcerias e apoios para implementação das ações;

- a criação de políticas públicas para apoio financeiro contínuo com vista à execução dos planos de salvaguarda e à manutenção das práticas culturais inventariadas.

\section{Reflexão final}

Não existem hoje domínios estanques no universo do patrimônio. As adjetivações cultural, natural, material ou imaterial constituem dimensões indissociáveis que se sobrepõem segundo diversas variantes em cada uma das manifestações culturais que representam a dimensão mais afetiva e criativa das culturas, constituindo assim uma das maiores riquezas da humanidade, mas também uma das mais vulneráveis.

O conceito de PCI, apesar de relativamente recente no vocabulário das ciências patrimoniais, foi-se consolidando através de políticas e práticas próprias nos mais variados contextos. No entanto, por ser um conceito simultaneamente redutor (apenas se refere a manifestações vivas) e abrangente (trazendo questões-chave para a democratização das culturas), devemos manter a atenção na forma, nos métodos e nas práticas utilizadas ao nível da sua salvaguarda.

Sob essa perspectiva, a tipologia de inventário à qual dedicamos este artigo constitui um passo essencial para o universo do patrimônio: do inventário meramente descritivo/passivo/fechado passa-se ao inventário vivo/ativo/em construção. Conscientes da relevância dos processos de IP em curso que vêm acontecendo de um e de outro lado do Atlântico, quisemos contribuir para a avaliação dos mesmos e para o desenvolvimento e reforço das boas práticas.

O estudo aqui apresentado analisa os métodos e as ferramentas utilizados nesse tipo de inventário tendo como base dois processos de patrimonialização, um no Brasil e outro em Portugal. Com esse objetivo reflete sobre as políticas de patrimônio imaterial desses países e apresenta uma proposta de métrica analítica, a Escala de Participação Cidadã, que permite avaliar a natureza e a qualidade participativa de cada uma das fases desses inventários.

$\mathrm{O}$ intuito final dessa métrica analítica é identificar, dentro dessas políticas 
culturais de inventariação, o impacto das experiências que se propõem a ser participativas, expondo os retornos (sociais, pessoais-afetivos e materiais), bem como o potencial de mudança de realidades preexistentes. Portanto, o processo participativo é aqui entendido como um mecanismo de promoção da diversidade e da integração cultural como uma ferramenta de diálogo, de informação e de reflexão, que possibilita o exercício da cidadania com o patrimônio como instrumento de reconhecimento de direitos culturais, sociais e econômicos. As experiências estudadas demonstraram que os inventários de PCI não terminam com a classificação/registro dos bens. Se, por um lado, a partir da classificação/registro, torna-se necessário acompanhar a evolução das manifestações e das respectivas medidas de salvaguarda (atualizando dados documentais, alimentando a conexão entre equipes, grupos, comunidades, adaptando os objetivos aos diferentes tempos), por outro lado é preciso garantir a construção de uma autonomia progressiva e crescente na gestão local do patrimônio pela mão dos/as seus/suas protagonistas, cujos interesses nem sempre coincidem com os de quem com eles promove o processo de patrimonialização.

\section{Referências}

ARANTES, Antônio Augusto.

(2001). Patrimônio imaterial e referências culturais. Tempo Brasileiro: Patrimônio Imaterial, n. 147. Rio de Janeiro: Tempo Brasileiro.

ARNSTEIN, Sherry. R. A.

(2004). Ladder of Citizen Participation. JAIP. vol. 35, n. 4, pp. 216-224.

BORDENAVE, Juan.

(1983). O que é participação? São Paulo: Editora Brassiliense.

CABRAL, Clara.

(2017). Social transformation with UNESCO heritage. EU-LAC Foundation's Newsletter, no 1 , July.

CASTRO, Maria Laura Viveiros de; FONSECA, Maria Cecília Londres.

(2008). Patrimônio imaterial no Brasil. Brasília: UNESCO, Educarte.

COHEN, John M.; UPHOFF, Norman T.

(2011/1980). Participation's place in rural development: seeking clarity through specifi city. In: CORNWALL, Andrea (ed.). The Participation Reader. London: Zed Books.

COSTA, Paulo.

(2013). 0 Inventário Nacional do Património Cultural Imaterial: da prática etnográfica à voz das comunidades. In: Políticas Públicas para o Património Cultural Imaterial na Europa do Sul: Percursos, Concretizações, Perspectivas. Lisboa: Direção-Geral do Património Cultural, pp. 93116.

DESSEIN, Joost; SOINI, Katriina; FAIRCLOUGH, Graham; HORLINGS, Lummina.

(2015). Culture in, for and as Sustainable Development. Conclusions from the Cost Action IS1007 Investigating Cultural Sustainability. Jyväskylä: Jyväskylä University Press \& European Cooperation in Science and Technology. 
FONSECA, Cecília Londres.

(1997). 0 patrimônio em processo: trajetória da política federal de preservação no Brasil. Rio de Janeiro: UFRJ, IPHAN.

FONSECA, Cecília Londres.

(2004). Os inventários nas políticas de patrimônio imaterial. Celebrações e Saberes da Cultura Popular: pesquisa, inventário, crítica, perspectivas. Série Encontros e Estudos, n. 5. Rio de Janeiro: Funarte.

FRITH, Simon.

(1996). Music and identity. In: HALL, Stuart; GAY, Paul du (eds). Questions of Cultural Identity. London, Thousand Oaks, New Dheli: Sage Publications, pp. 108-127.

HANDLER, Richard.

(1988). Nationalism and the politics of culture in Quebec. Madison: The Wisconsin University Press.

HANDLER, Richard.

(1994). Is identity a useful cross-cultural concept? In: GILLIS, J. R. Commemorations: the politics of national identity. Princeton: Princeton University Press, pp. 27-40.

HAWKES, John.

(2001). The fourth pillar of sustainability: culture's essential role in public planning, Victorian Cultural Development Network. Melbourne: Common Ground P/L.

\section{INSTITUTO DO PATRIMÔNIO HISTÓRICO E ARTÍSTICO} NACIONAL.

(2015). Com a palavra, os detentores. Brasília, DF: Departamento de Patrimônio Imaterial/Iphan. Disponível em: http://portal.iphan.gov.br/uploads/ckfinder/a rquivos/com_a_palavra_os_detentores.pdf. Acesso em: 27 maio 2019.

\section{INSTITUTO DO PATRIMÔNIO HISTÓRICO E ARTÍSTICO} NACIONAL.

(2014). Dossiê Matrizes do Samba Carioca: partidoalto, samba de terreiro, samba-enredo. DF: Departamento de Patrimônio Imaterial/Iphan. Disponivel em: http://portal.iphan.gov.br/uploads/ckfinder/a rquivos/Dossi-
\%20Matrizes\%20do\%20Samba.pdf. Acesso em: 16 mar. 2015.

INSTITUTO DO PATRIMÔNIO HISTÓRICO E ARTÍSTICO NACIONAL.

(2012). Patrimônio imaterial: disposições constitucionais: normas correlatas: bens imateriais registrados. Flávia Lima e Alves (Org). Brasília: Senado Federal, Subsecretaria de Edições Técnicas. Disponível em: https://www2.senado.leg.br/bdsf/bitstream/h andle/id/496320/000934175.pdf? sequence=1. Acesso em: 16 jul. 2017.

\section{INSTITUTO DO PATRIMÔNIO HISTÓRICO E ARTÍSTICO} NACIONAL.

(2000). Inventário Nacional de Referências Culturais, Manual de Aplicação. Brasília: DID.

INTERNATIONAL ASSOCIATION FOR PUBLIC PARTICIPATION (IAP2).

(2014). Public Participation Spectrum. Disponivel em:

https://cdn.ymaws.com/www.iap2.org/resourc e/resmgr/foundations_course/IAP2_P2_Spectr um_FINAL.pdf. Acesso em: 07 jun. 2018.

MENDONÇA, Elizabete de Castro.

(2017). Processos de patrimonialização e musealização no âmbito do Programa Nacional de Patrimônio Imaterial: Desafios e potencialidades para a salvaguarda de bens registrados (Brasil). In: HOMEN, Paula Menino; ROCHA, Marlene; HEES, Luciana Justiniani (Org.). Ensaios e Práticas em Museologia. Porto: Universidade do Porto / Faculdade de Letras / Departamento de Ciências e Técnicas do Património, v. 6. pp. 50-65.

MENDONÇA, Elizabete de Castro.

(2015). Programa Nacional de Patrimônio Imaterial e Museu: apontamentos sobre as estratégias de articulação entre processos de Patrimonialização e Musealização. Museologia e Interdisciplinaridade, v. 8, pp. 88-106.

MIGUEL, Ana Flávia.

(2017). Kola San Jon. In: PRATO, Paolo; HORN, David (eds). Bloomsburry Encyclopedia of Popular Music of the World, vol XI Genres: Europe. London, New York: Bloomsbury, pp. 439-441. 
MIGUEL, Ana Flávia.

(2016). Skopeologias: músicas e saberes sensíveis na construção partilhada do conhecimento. Tese de doutoramento apresentada ao Departamento de Comunicação e Arte, Universidade de Aveiro.

MIGUEL, Ana Flávia.

(2010). Kola San Jon, Música, Dança e identidades Cabo-Verdianas. Dissertação de mestrado apresentada ao Departamento de Comunicação e Arte, Universidade de Aveiro.

MIRANDA, Marcos Paulo de Souza.

(2008). 0 inventário como instrumento constitucional de proteção ao patrimônio cultural brasileiro. Revista Jus Navigandi, Teresina, ano 13, n. 1754. Disponível em: https://jus.com.br/artigos/11164. Acesso em: 16 jul. 2017.

NOGUEIRA, Nilcemar.

(2015). o Centro Cultural Cartola e o Processo de Patrimonialização do Samba Carioca. Tese de Doutorado apresentada ao Instituto de Psicologia, Universidade do Estado do Rio de Janeiro.

NOGUEIRA, Nilcemar.

(2014). A patrimonialização do samba. In: MENDONÇA, Elizabete de Castro; SILVA, Júnia Gomes da Costa Guimarães e (Orgs.). Bens culturais musealizados: políticas públicas, preservação e gestão. Rio de Janeiro: UNIRIO, Escola de Museologia, pp. 33-44.

PATEMAN, Carole.

(1992). Participação e teoria democrática. Tradução de Luiz Paulo Rouanet. Rio de Janeiro: Paz e Terra.

PEIXOTO, Paulo.

(2017). A linguagem consensual do patrimônio. In: SOTRATTI, Marcelo Antonio; DUARTE PAES, Maria Tereza (Orgs.). Geografia, Turismo e Patrimônio Cultural: Identidades, Usos e Ideologias. São Paulo: Annablume Editora, pp. 127-140.

RIBEIR0, Jorge Castro.

(2012). “Inquietação, Memória e Afirmação no Batuque: Música e Dança Cabo-Verdiana em Portugal." Tese de doutoramento apresentada na Universidade de Aveiro. Disponível em:

http://hdl.handle.net/10773/7559. Acesso em: 15 ago. 2013.

SANCHO QUEROL, Lorena.

(2017). PARTeCIPAR. Ensaio formal sobre o conceito, as práticas e os desafios da Participação Cultural em museus. Etnicex. Revista de Estudios Etnográficos, n. 8, pp. 83-100.

SANCHO QUEROL, Lorena.

(2016). El Patrimonio Cultural Inmaterial y la Sociomuseologia: un estudio sobre inventarios. Cadernos de Sociomuseologia, Coleção Série Estudos Pós-Graduados, n. 1 (nova série).

SANCHO QUEROL, Lorena.

(2013). Para uma gramática museológica do (re)conhecimento: ideias e conceitos em torno do inventário participado, Sociologia, Revista da Faculdade de Letras da Universidade do Porto, vol. 25, pp. 165-188.

SANTOS, Boaventura de Sousa.

(2007). Beyond Abyssal Thinking: From Global Lines to Ecologies of Knowledges, Review, XXX, 1, pp. 45-89.

SARD0, Susana.

(2018). Shared Research Practices on and about music: toward decolonizing colonial ethnomusicology. In: MARTÍ, Josep; GÚTIEZ, Sara Revilla (eds.). Making Music, Making Society. Cambridge: Cambridge Scholars Publishing, pp. 217-238.

SARD0, Susana.

(2016). Ethnomusicology and its Sisyphus. Interknowledge, dialogue and prudence for a disciplinary (re)classification. In: ALLGAYERKAUFMANN, Regine (ed.). World Music Studies. Publisher: Logos Verlag, pp. 149-166.

SARD0, Susana.

(2010). Guerras de Jasmim e Mogarim: Música, Identidade e Emoç̃̃es em Goa. Alfragide: Texto Editora.

SILVESTRIN, Mônia Luciana; DIANOVSKY, Diana.

(2017). Reconhecimento do patrimônio imaterial, mercado e política: reflexões a partir de uma experiência de Estado. Revista Andaluza de 
Antropología, n. 12, 'Patrimonio Inmaterial: reduccionismos, conflictos instrumentalizaciones', pp. 70-93. Disponível em:

https://dialnet.unirioja.es/servlet/articulo?co digo=5971855 Acesso em: 16 jul. 2017.

SMITH, Laurajane.

(2006). Uses of Heritage. London: Routledge.

STAGE, Karsten; INGERSLEV, Karen.

(2015). Participation as assemblage. Introducing assemblage as a framework foranalysing participatory processes and outcomes. Conjunctions: Transdisciplinary Journal of Cultural Participation, vol. 2, n. 2. Disponível em:

https://tidsskrift.dk/tcp/article/view/22923. Acesso em: 25 maio 2019.

UNESCO.

(2003). Convenção para a Salvaguarda do Patrimônio Cultural Imaterial, de 17 de outubro de 2003. In: LIMA E ALVES, Flávia (Org.), Patrimônio imaterial: disposições constitucionais: normas correlatas: bens imateriais registrados. pp.37-54. Brasília: Senado Federal, Subsecretaria de Edições Técnicas. Disponível em: https://www2.senado.leg.br/bdsf/bitstream/h andle/id/496320/000934175. pdf? sequence=1. Acesso em: 16 jul. 2017.
UNESCO.

(1989). Recomendação para a Salvaguarda da Cultura Tradicional e Popular, Disponível em: http://www.portaldoconhecimento.gov.cv/bits tream/10961/238/4/Anexo\%203\%20-

\%20Doctos\%20Unesco.pdf. Acesso em: 28 maio 2019.

VIANNA, L; TEIXEIRA, J. G.

(2008). Patrimônio Imaterial, performance e identidade. Concinnitas. vol. 1, n. 12. Rio de Janeiro: Universidade Estadual do Rio de Janeiro / Instituto de Artes.

\section{Recebido em}

maio de 2019

\section{Aprovado em}

abril de 2020 